\title{
AGILE LEARNING LOOPS - COMBINING AGILE APPROACHES IN HIGHER EDUCATION PROGRAMS
}

\author{
Karsten Böhm and Yvonne Unnold \\ FH Kufstein Tirol - University of Applied Sciences \\ Andreas-Hofer-Str.7, A-6330 Kufstein, Austria
}

\begin{abstract}
Learning processes within higher education programs increasingly focus on applying concepts rather than just facilitating the comprehension of concepts studied. Some of the curricular elements commonly used can be classified as project-based exploratory learning activities that usually pose unique challenges for students. Examples of such activities include theses or individual projects. To be successful in these tasks, students require more agility and flexibility in designing, managing and implementing their project. This contribution addresses those requirements by introducing introduces a concept that adopts the SCRUM methodology to facilitate project-based learning processes in higher education. It discusses application scenarios and benefits of a more iterative and agile approach called Agile Learning Loops (ALL), describes the new methodology in detail and addresses its application potential.
\end{abstract}

\section{KEYWORDS}

SCRUM, Learning Framework, Project-Based Learning, Agile Learning, Learning Loops

\section{INTRODUCTION}

Higher education should enable students to build advanced scientific and abstract thinking skills for problem-solving that they can apply in their professional career after their studies in their respective subjects. Thus, courses should not only provide an opportunity for the acquisition of knowledge. It is imperative that they train students to apply this knowledge in chalenging and real-worldscontexts. Project-Based Learning (PBL) (Chen and Yang, 2019) provides valuable learning opportunities to apply their knowledge, including previously acquired knowledge or new insights that students discover as part of the project. Generally, PBL activities are student-driven and involve limited supervision or guidance by lecturers. The open character of PBL poses a particular challenge for students and facilitators because much flexibility is required to reach curricula learning outcomes.

Learning Loops (Kolb, 2014) has been distinguished in didactic literature as an effective way to deepen understanding and enhance skills via iterations that allow opportunities to learn from mistakes and incorporate insights gained through feedback loops (e.g., iteration). However, due to the time and resource constraints in many curricula, the provision of opportunities for circular learning is not always feasible.

In the realm of computer sciences, SCRUM (Schwaber, 2007; Srivastava, Bhardwaj and Saraswat, 2017) has been established as a methodology to develop software systems in an agile way, using iteration in individual development cycles to improve the process and to react to changed environmental conditions or project goals. However, SCRUM methodology can also enable the implementation of learning loops for specific projects. The present study's core goal is to demonstrate the applicability of the SCRUM methodology for teaching purposes in higher education subjects that corporate PBL.

Surprisingly, research published on this topic is limited. There are a few papers on the use of SCRUM for educational purposes in schools (i.e., Royle and Nikolic, 2016). In the realm of e-learning, SCRUM has been used to manage the process of designing course content (Supangat et al., 2019; Vogelzang, Admiraal and Driel, 2019). However, to the authors best knowledge, SCRUM has not yet been used for an educational design in the area of higher education. 
The paper is organised as follows: Section 2 describes the concept of Agile Learning Loops (ALL) as a learning design framework with references to loop-style learning models and presents the ALL process, including associate roles and activities. Section 3 elaborates on the current application of ALL in the context of a higher education program, and section 4 outlines the present-day IT-tools supporting the implementation of ALL. Finally, section 5 concludes the paper with a summary and an outlook on planned next steps.

\section{THE CONCEPT OF AGILE LEARNING LOOPS}

The concept of Agile Learning Loops (ALL) focuses on a methodological transfer of the SCRUM methodology (Schwaber, 2007) and of the organisational concepts of loop-oriented learning models, such as Single-, Double- and Triple-Loop-Learning (Argyris and Schön, 1978), as an organisational design framework into the context of a learning situation in higher education, and, thus, into a learning design framework for $P B L$. The intention of this transfer is to provide an agile supporting framework for student-oriented tasks that (a) helps the learner structure the learning process while maintaining maximal flexibility for the project and (b) affords coaching opportunities for the lecturer to assist the student throughout the project with minimal interference in the learning process.

The aspects that are taken into account for this transfer include a) the roles, b) the activities, and c) the process defined in SCRUM that need to be transferred in a meaningful way to the ALL methodology.

\subsection{Loop Style Learning Models}

The research on Loop Style Learning Models refers back to (Argyris and Schön, 1978), who primarily studied organisational learning processes and developed several loop learning models, shown in figure 1, namely Single-Loop-Learning (SLL), Double-Loop-Learning (DLL), and Triple Loop Learning (TLL). Applications of these learning models are also relevant for higher education processes and can be applied to our framework.

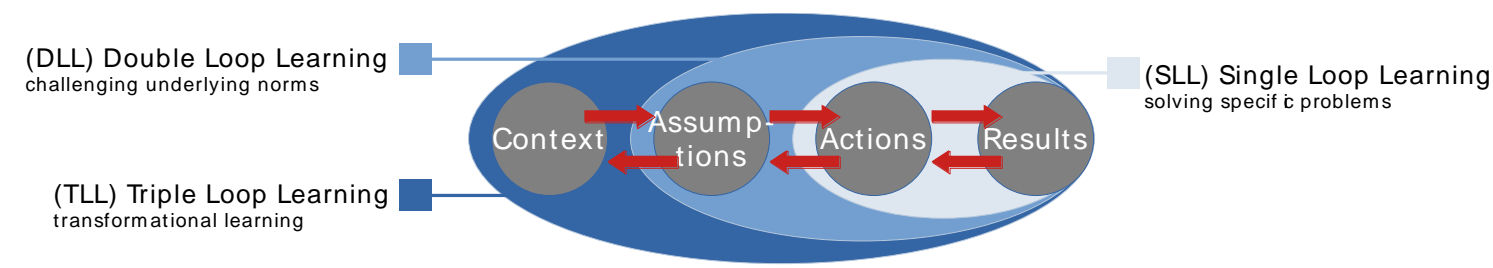

Figure 1. Association of the different Loop Learning Methods with increasing reflection and learning impact process per (Argyris and Schön, 1978)

SLL refers to solving a specific problem and is usually the primary tool for building necessary problem-solving skills in the first phases of higher education programs (e.g., by solving exercises). It represents a simple control loop that provides a stimulus and a response which generates a positive effect when the right solution is found. Learning also occurs when mistakes are identified on a repetitive execution of this loop ("trial and error"). Formerly, students were asked to find solutions on problems that are posed by the professors and thus finding the right solution is the standard mode for most students. This type of learning remains on the level of solving a specific problem and does not challenge the underlying assumptions or norms. However, developing critical thinking skills ("asking why" attitude) is one of the core features of a higher education program and reflected in DLL, which requires students to solve problems, question underlying norms, and identify root causes. Students often struggle when transitioning from SLL to DLL because the latter requires solving more complex scientific tasks. Support methodologies, like ALL, can assist students with this transition.

The optimal learning methodology in higher education is Triple Loop Learning (TLL), which can be described as transformational learning. TLL trains students to take the underlying context into account and enables them to derive universal patterns that are valid independently of the specific application context - leading to a transformational change in the learner. 


\subsection{The Agile Learning Loop (ALL) Process}

The general SCRUM process is illustrated in figure 2 below. It already includes some slight adaptations to the ALL methodology. The iterative nature of the process is organised into so-called sprints, each of which addresses a part of the possible product features. Sprints have a typical duration of about 2-3 weeks and reflect the stakeholders' project plan and development team's timeline of task sequence and completion. When planing the project, tasks are divided into subtasks, organised via the Product Backlog, and assigned a sprint phase based on relevance and complexity. The Sprint Backlog contains all planned activities for each consecutive sprint. During a sprint, the development team holds brief daily meetings to plan the day's work (Daily Scrum) and identify problems (impediments) that may affect the timely completion of tasks. The latter is usually depicted in Kanban-style planning boards and progress charts. This process helps coordinate the team and provides transparency among all stakeholders. Upon completion of a sprint, the team evaluates the results and reflects on the lessons learned (a process called 'retrospective'). Then the cycle starts again. Retrospectives provide an opportunity to evaluate the development process, the (current) product features, and the productivity of the involved team members. Moreover, they enable the team to improve the mentioned aspects by identifying and removing impediments from the process.

The ALL framework adopts most SCRUM concepts and integrates them into the context of a learning framework. The product backlog can be adopted in a very similar way: the artefact of a product backlog helps the learner organise and document the project tasks and determine the tasks' level of usefulness (relevance) and difficulty in the planning phase. For the lecturer, this opens up another opportunity for coaching and to give guidance on product backlog items. In contrast to other learning frameworks, the tasks' detailed documentation makes the process much more transparent and specific for all stakeholders (student, supervisors, and eventually peers).

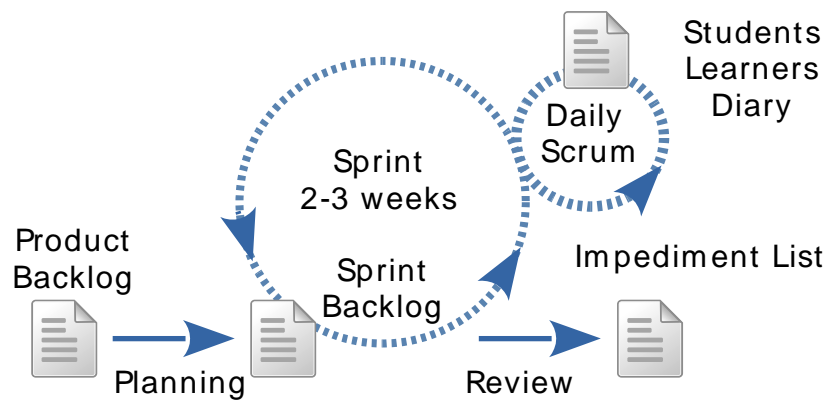

Figure 2. Illustration of a Sprint within a SCRUM process with some adaptions to the ALL methodology

The user stories (the term used for functional requirement in SCRUM) in the backlog describe the specific learning outcomes from the learners' perspective. The task of articulating their learning outcomes represents the students' first step towards grasping the complexity of the problem; simultaneously, this provides a coaching possibility for the lecturer.

Students complete the planned tasks during a sprint and reflect daily on their progress in their learners' diary. This effort, which is usually executed by the development team, might initially appear redundant; however, it serves two purposes in ALL methodology. (1) It encourages students to reflect on achievements and upcoming tasks. When articulated in this way, project problems and overall progress become explicit (e.g., adding problems to the impediment $\log$ ) and can more easily be discussed with the lecturer. Furthermore, (2) it helps students plan a clear daily timeline for their tasks. This is important, as daily timelines help students stay on task when completing complex projects (such as a thesis).

After a sprint, students and lecturers hold a sprint review. They reflect on the performance of the last sprint, evaluate their progress in the sprint backlog and the impediment list. This retrospective phase is a prime opportunity for coaching, as it highlights deficits and unresolved questions. Moreover, it helps improve student performance on the next iteration (sprint). Without the backlog and impediment list, effective coaching poses a challenge because lecturers are not involved in the sprint execution. Without ALL, the situation lacks the transparency required for thorough analysis. In contrast, with ALL methodology, progress is much more visible due to the framework structure. With every iteration, it becomes easier to have an open reflection because the 
benefit becomes more obvious for the students. This also helps improve the relationship between the students and their lecturer, as students recognise that the lecturer is supporting rather than judging their work's quality and progress. Well-executed retrospectives improve team performance and create trust among the group (Paasivaara et al., 2013), (McHugh, Conboy and Lang, 2012).

An important aspect for the retrospective is a proper "Definition of Done" (DoD) within the ALL methodology. It is a good way of discussing an outcome in terms of its relation to scientific work (rigour and relevance). Moreover, it is much more useful from a didactic point of view because discussing important aspects of scientific work is not abstract for students when it is closely related to their specific project or task. This makes for a good learning opportunity. Table 1 summarises and compares the most relevant process artefacts in SCRUM and ALL.

Table 1. Comparison of the most important process artefacts in SCRUM and ALL

\begin{tabular}{|c|c|c|}
\hline Artefact & SCRUM Methodology & ALL Methodology \\
\hline Product Backlog & Planned product features & Planned project activities \\
\hline Sprint Backlog & Features developed in the current sprint & Activities tackled in the current sprint \\
\hline Impediment List & List of project impediments for the team & $\begin{array}{l}\text { List of project impediments for the } \\
\text { student }\end{array}$ \\
\hline Daily Scrum & Daily team meeting for coordination & $\begin{array}{l}\text { Individual reflection of the student on } \\
\text { progress }\end{array}$ \\
\hline Learners' Diary & $(\mathrm{n} / \mathrm{a})$ & $\begin{array}{l}\text { Brief documentation of Daily Scrum } \\
\text { outcomes }\end{array}$ \\
\hline
\end{tabular}

\subsection{Roles in the ALL Methodology}

Multiple roles must be assigned to implement SCRUM effectively, execute the overall process, and meet specific sub-tasks and associated goals. While one role focuses on the capability to react to unprecedented changes and unexpected challenges, another focuses on the proper application of SCRUM methodology. SCRUM methodology is designed to be implemented without any changes or adaptations. However, in the context of ALL methodology, some adaptations or interpretations are necessary.

The primary roles in SCRUM include the Scrum Master (SM), the Product Owner (PO), and the Development Team (DEV). Table 2 provides a brief definition of these roles in SCRUM and ALL methodologies.

Table 2. Comparison of the most important process aspects in SCRUM and ALL

\begin{tabular}{|c|c|c|}
\hline Role & SCRUM Methodology & ALL Methodology \\
\hline $\begin{array}{l}\text { SCRUM Master } \\
\text { (SM) }\end{array}$ & $\begin{array}{l}\text { A facilitator for the process that } \\
\text { supports the SCRUM process and } \\
\text { removes impediments for the team }\end{array}$ & $\begin{array}{l}\text { A supervisor (lecturer) who guides } \\
\text { students in the agile process and sprints to } \\
\text { help them achieve their planned outcomes }\end{array}$ \\
\hline $\begin{array}{l}\text { Product Owner } \\
\text { (PO) }\end{array}$ & $\begin{array}{l}\text { The stakeholder that is responsible for } \\
\text { the quality and functional requirements } \\
\text { of the final product and an expert in the } \\
\text { domain that the product is designed for }\end{array}$ & $\begin{array}{l}\text { A 'shared role' between student and } \\
\text { supervisor (lecturer) with both being } \\
\text { accountable for different aspects of the } \\
\text { final result }\end{array}$ \\
\hline $\begin{array}{l}\text { Development Team } \\
\text { (DEV) }\end{array}$ & $\begin{array}{l}\text { A group of developers that carries out } \\
\text { the product development tasks in an } \\
\text { iterative and agile development process }\end{array}$ & $\begin{array}{l}\text { The role of the lead student. Potentially, } \\
\text { peers may be involved at given moments; } \\
\text { however, this role is not designed to be } \\
\text { carried out by a team. }\end{array}$ \\
\hline
\end{tabular}

In a higher education context, students assume two roles: the role of the product owner and the role of the developer ${ }^{1}$. This is because the student is responsible for implementing the project as well as for the final result. For this reason, the DEV role is usually not designed as a team role in ALL methodology. Instead, it is a role to be carried out by a single student who may be supported in this role through collaboration by peers involved in the project or the project review.

1 We are using the role definition 'developer' here as it is defined that way in SCRUM. However, ALL is not restricted to software developing projects, thus the developer-role can be understood as the role the builder or creator of the various project artefacts 
In contrast, the lecturer (supervisor) primarily assumes the role of Scrum Master (SM), who is responsible for supporting the overall process and serves as a liaison for other main stakeholders involved (e.g., an external project sponsor). When applying ALL methodology, the SM's role is not limited to ensuring the application of the methodology. Here, the role of SM also includes counselling and coaching students in the field of scientific work. Moreover, the lecturer defines some of the formal requirements (e.g., scientific rigour). Therefore, the PO's role is shared to some extent. In SCRUM, this could pose a potential source of conflict as roles are usually not split in this methodology. However, when applying ALL, the shared role allocation can serve as a specific coaching opportunity to improve the project result.

\subsection{Activities and Artifacts in the ALL Process}

Some activities and artefacts are central to SCRUM methodology and are used to support teams in executing their development processes in an agile and efficient way. In order to integrate SCRUM activities and artefacts with the ALL methodology for application in higher education, some important aspects need to be adapted to suit the new context. Table 3 articulates the changes necessary.

Table 3. Adaptation of typical SCRUM activities \& artefacts to the ALL Methodology

\begin{tabular}{|c|c|c|}
\hline Artefact & Description in SCRUM & Adaptation for use in ALL \\
\hline Product Increment & $\begin{array}{l}\text { The development progress between } \\
\text { different sprints }\end{array}$ & $\begin{array}{l}\text { Used to measure the progress in the } \\
\text { project (reflection on learnings) }\end{array}$ \\
\hline Velocity & $\begin{array}{l}\text { The amount of functional } \\
\text { requirements implemented in } \\
\text { comparison to previous sprints, } \\
\text { measured with Story Points; } \\
\text { represents the development speed of } \\
\text { the team over time }\end{array}$ & $\begin{array}{l}\text { Only useful if stories are equipped with } \\
\text { story points, and the estimations are } \\
\text { correct; as the DEV is a person and the } \\
\text { project objective often of exploratory } \\
\text { nature, velocity will vary significantly, } \\
\text { and estimations may be more or less } \\
\text { correct }\end{array}$ \\
\hline Story Point Estimation & $\begin{array}{l}\text { A measurement to express the } \\
\text { usefulness and the complexity of a } \\
\text { functional requirement described in a } \\
\text { user story }\end{array}$ & $\begin{array}{l}\text { Used to quantify the complexity of the } \\
\text { tasks in the planning and the retrospective } \\
\text { phases; the supervisor could provide a } \\
\text { usefulness estimation }\end{array}$ \\
\hline Definition of Done & $\begin{array}{l}\text { An agreement among the team on } \\
\text { the properties that an implementation } \\
\text { of a functional requirement must } \\
\text { meet to be considered complete }\end{array}$ & $\begin{array}{l}\text { In an academic context, a project-specific } \\
\text { definition of rigour and relevance may be } \\
\text { a variable used to define the outcomes that } \\
\text { must be achieved in order for a task to be } \\
\text { considered done }\end{array}$ \\
\hline Code Review & $\begin{array}{l}\text { Quality assessment of the resulting } \\
\text { code via peer review of individual } \\
\text { segments }\end{array}$ & $\begin{array}{l}\text { As the DEV is not a team effort, this } \\
\text { aspect is of little importance for ALL; } \\
\text { might be used for specific feedbacks }\end{array}$ \\
\hline Burndown Chart & $\begin{array}{l}\text { A chart listing the number of open } \\
\text { tasks in the backlogs over time, } \\
\text { presenting a graphic depiction of the } \\
\text { development speed }\end{array}$ & $\begin{array}{l}\text { Could be used in later stages of ALL with } \\
\text { projects involving a large number of } \\
\text { stories and when story points are used }\end{array}$ \\
\hline Kanban-Board & $\begin{array}{l}\text { A table listing the different activities } \\
\text { in a given sprint, reflecting their } \\
\text { current status; a primary method } \\
\text { used to coordinate DEV }\end{array}$ & $\begin{array}{l}\text { Used to facilitate reflection and coaching; } \\
\text { serves to make the student-centric process } \\
\text { (more) transparent and to provide coach- } \\
\text { ing opportunities for the supervisor. }\end{array}$ \\
\hline Backlog Grooming & $\begin{array}{l}\text { The process of reviewing the } \\
\text { backlogs for functional requirements } \\
\text { that are no longer relevant and can } \\
\text { be removed; carried out by the PO }\end{array}$ & $\begin{array}{l}\text { Used as a part of the retrospective; } \\
\text { enables the supervisor to evaluate and } \\
\text { help to adjust the project focus }\end{array}$ \\
\hline $\begin{array}{l}\text { Story Writing } \\
\text { Workshop }\end{array}$ & $\begin{array}{l}\text { An activity to formalise the } \\
\text { definition of work done in the } \\
\text { project; usually a team effort at the } \\
\text { commencement of the project or } \\
\text { sprint }\end{array}$ & $\begin{array}{l}\text { Used to help students set up their project } \\
\text { and get started (assist in overcoming } \\
\text { potential writers' block) }\end{array}$ \\
\hline
\end{tabular}




\begin{tabular}{lll} 
User Story & $\begin{array}{l}\text { A description in layman's terms of } \\
\text { the functional requirements so that } \\
\text { these can be understood by the } \\
\text { domain expert (PO) as well as the } \\
\text { team (DEV) }\end{array}$ & $\begin{array}{l}\text { Used to define project tasks and } \\
\text { outcomes; can also be used to coach and } \\
\text { help improve individual stories }\end{array}$ \\
$\begin{array}{l}\text { An aggregation of different user } \\
\text { stories that have a close relation to } \\
\text { each other or represent a more } \\
\text { abstract description that is not (yet) } \\
\text { specific enough to be implemented }\end{array}$ & $\begin{array}{l}\text { Used for pre-structured individual } \\
\text { projects, such as a final thesis, to provide } \\
\text { an initial and abstract structure for the } \\
\text { components that should be part of the } \\
\text { final product }\end{array}$ \\
\hline
\end{tabular}

\section{APPLICATION OF ALL METHODOLOGY}

The ALL methodology has shown to be applicable across the curriculum at the author's university as many lecturers and courses now regularly integrate PBL-oriented teaching and learning. This trend is likely to grow even further, given the increased focus on applied learning in our education programs across all subjects and domains.

This study proposes that the new methodology be used for two primary purposes: (1) to facilitate the supervision of final thesis projects (both in the Bachelor's and Master's programs), in which all students are assigned a mentor for their specific topic, and (2) to guide Individual Projects (IP) associated with a Bachelor's program.

An IP is a course that allows students to work individually on a wide range of topics while coached by degree program faculty. In contrast to final thesis projects, IPs are introduced at the commencement of the program and are designed to help students (a) build a scientific skillset and (b) provide an opportunity to in the program to "fail without failing" . Both settings require a learning process tailored to students learning needs and progress. Thus, the support of the lecturer needs to respond to students' individual needs and requires an agile teaching approach.

The ALL method provides a specific framework for the required coaching processes and retains flexibility for addressing individual needs. Figure 3 illustrates the application of ALL over the course of one semester (roughly three months). The four cycles planned for the individual projects are designed for a duration of approx. three weeks each.

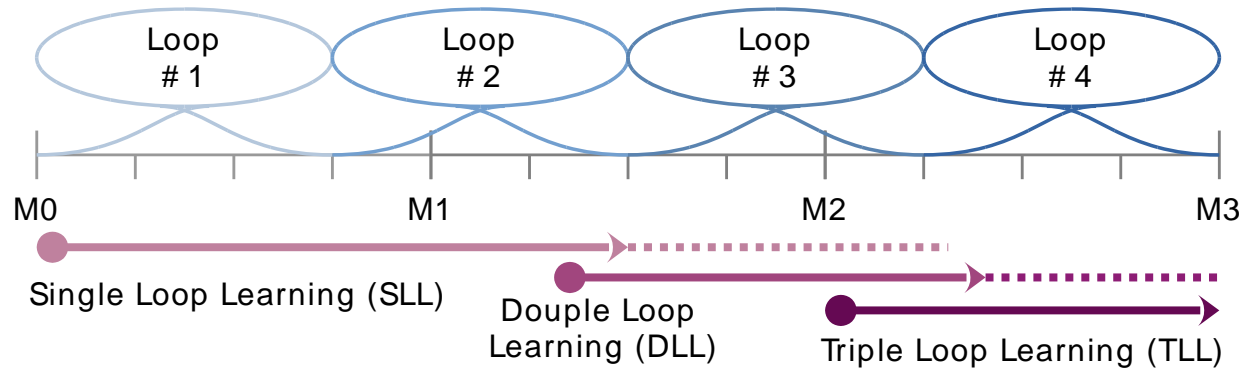

Figure 3. Relationship between the loops within a semester cycle and the distinct types of loop learning occuring over time

In each cycle (or loop), students resolve individual tasks within the project under faculty supervision. Initially, loops will be primarily problem-focused and constitute SLLs. Using ALL methodology, a transition to DLL and finally TLL will occur over the course of the project.

2 Usually, courses and assessments are designed with the requirement to reach a successful result in a first attempt. Such an expectation tends to discourage students risk-taking. However, when students are allowed to make and reflect on errors and mistaken initial approaches these can constitute optimal situations for successful and sustainable learning. Thus it is important that IPs provide a space for trial and error, reflection and assessment. 


\section{IT-TOOLS TO SUPPORT ALL METHODOLOGY}

For the implementation of ALL methodology, tools designed to support the SCRUM process can be used to help organise and facilitate the ALL process. Commercial tools, such as JIRA ${ }^{3}$ from Atlassian, may be used for this purpose (Li, 2018); however, the author decided to use Redmine ${ }^{4}$ (Lesyuk, 2016) with the Agile Plugin and the Boostmine Theme ${ }^{5}$. The reason for this tool choice is two-fold. For one, Redmine is an extensible and stable open-source software system; it is hence user-friendly and free of charge in terms of license fees. Secondly, students in computer sciences are generally familiar with the software from other contexts of their studies, which reduces their learning curve.

Redmine applies the concept of ticket-based activities assigned to members of the project team. The Agile Plugin implements a Kanban-style depiction of the different tickets based on status. The tool can be easily adapted to different needs, e.g. the activity status, the implicit workflows that result from activites status transitions, or the definition of custom attributes. Therefore, it can be effortlessly configured to meet the needs of ALL methodology. To configure the tool for use with ALL, two roles must be defined (Student and Supervisor). Moreover, the status of activities should include "New-SprintBacklog", "New-ProjectBacklog", "InProgress", "Feedback" and "Done". Figure 4 provides an interactive Kanban chart that displays the current activities together with their current status and the corresponding assignee.

Another important aspect of ALL methodology is a way to take notes on the individual project without adhering to a formal structure. The note-taking function is needed for two purposes: collecting random ideas and maintaining the research diary. 'Random ideas' are notes on thoughts that might not fit into a specific project activity or do not serve a specific purpose. Usually, they are written down in an ordinary notebook; however, the Redmine system provides the possibility to use the included Wiki-system for a quick and low-tech way of taking these notes.

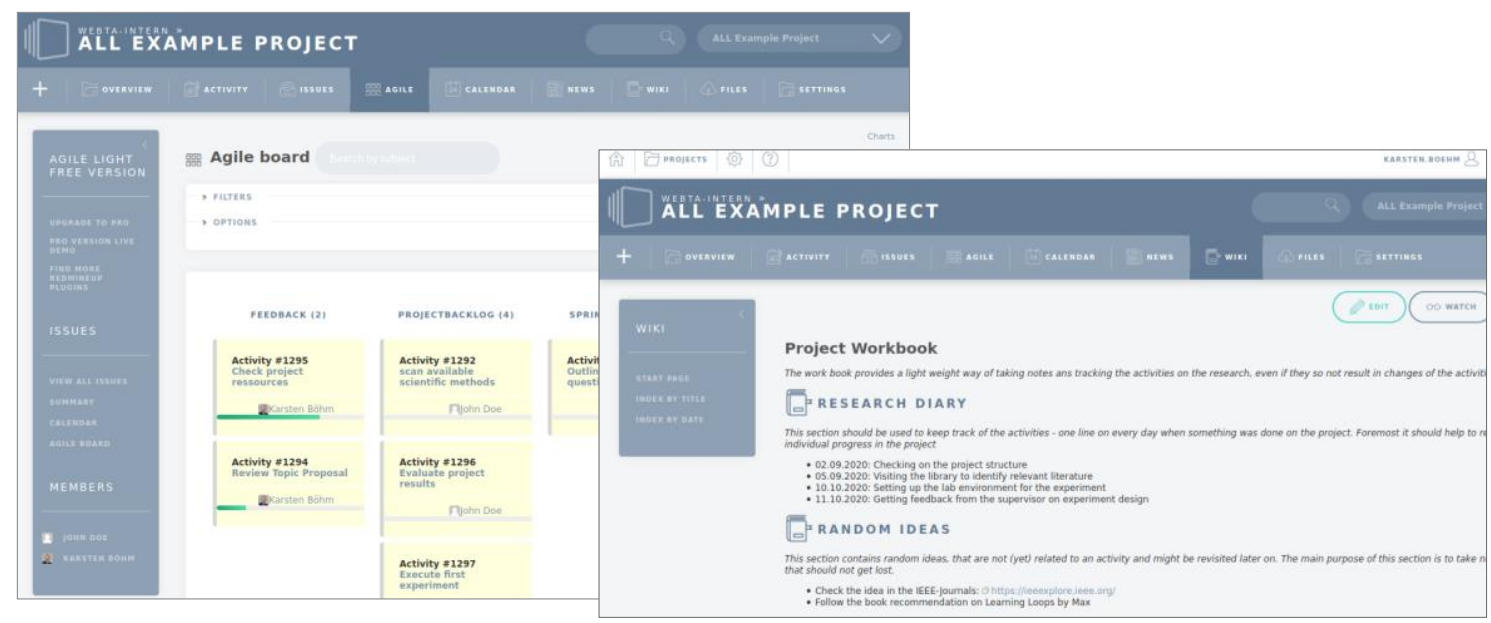

Figure 4. Kaban Board (left) to display and manage active tasks together with their status and Workbook for ALL (right) based on the existing Wiki-functionality in Redmine

The system's note-taking function allows students to link random ideas to other parts of the project (e.g. activities or documents). Figure 4 shows an example of such a wiki entry. The other crucial note-taking purpose of the project workbook is the Research Diary, which student keep to report their daily progress via a single-line entry. This daily routine provides an opportunity for students to reflect on the time spent on the project and the specific progress achieved. Moreover, these entries capture the project process and can be helpful when coaching or addressing (unexpected) challenges during the project.

The JIRA product is described here: https://www.atlassian.com/de/software/jira/scrum-boards

More information on RedMine can be found here: https://www.redmine.org/

More on the Agile Plugin can be found here: https://www.redmineup.com/pages/plugins/agile and the used theme is documented here: https//bestredminetheme.com/boostmine/ 


\section{SUMMARY}

This study outlines the methodology of Agile Learning Loops (ALL), a learning design framework inspired by the SCRUM methodology, and shows how it can be applied to PBL-oriented learning situations in higher education settings. Through minor modification and adaptation, SCRUM features can be integrated into ALL to help students transition between the three Loop Learning Methods, from SLL to DLL and then to TLL. Moreover, this approach strengthens students' problem solving and critical thinking skillsets and fosters appropriate time and task management skills. Finally, this unique integration of methodologies enables lecturers to enhance their mentorship in PBL, gives students relevant experience in project management, and utilises tools established and proven effective in their career field.

The respective process, activities and roles of the methodology in a Higher Education setting have been described and the application scenario and the tooling support have been outlined. The formal evaluation of this learning design framework will be subject to further research, but first experiences from the ongoing application of ALL will be reported at the conference.

\section{REFERENCES}

Argyris, C. and Schön, D. A. (1978) Organizational Learning: A Theory of Action Perspective. Addison-Wesley Publishing Company.

Chen, C.-H. and Yang, Y.-C. (2019) 'Revisiting the effects of project-based learning on students' academic achievement: A meta-analysis investigating moderators', Educational Research Review, 26, pp. 71-81. doi: 10.1016/j.edurev.2018.11.001.

Kolb, D. A. (2014) Experiential Learning: Experience as the Source of Learning and Development. FT Press.

Lesyuk, A. (2016) Mastering Redmine. Packt Publishing Ltd.

Li, P. (2018) Jira Software Essentials: Plan, track, and release great applications with Jira Software, 2nd Edition. Packt Publishing Ltd.

McHugh, O., Conboy, K. and Lang, M. (2012) 'Agile Practices: The Impact on Trust in Software Project Teams', IEEE Software, 29(3), pp. 71-76. doi: 10.1109/MS.2011.118.

Royle, K. and Nikolic, J. (2016) 'A modern mixture, agency, capability, technology and "scrum": agile work practices for learning and teaching in schools', 3. doi: 10.30845/jesp.

Paasivaara, M. et al. (2013) 'Teaching students global software engineering skills using distributed Scrum', in 2013 35th International Conference on Software Engineering (ICSE). 2013 35th International Conference on Software Engineering (ICSE), pp. 1128-1137. doi: 10.1109/ICSE.2013.6606664.Schwaber, K. (2007) The Enterprise and Scrum. Microsoft Press.

Srivastava, A., Bhardwaj, S. and Saraswat, S. (2017) 'SCRUM model for agile methodology', in 2017 International Conference on Computing, Communication and Automation (ICCCA). 2017 International Conference on Computing, Communication and Automation (ICCCA), pp. 864-869. doi: 10.1109/CCAA.2017.8229928.

Supangat, S. et al. (2019) 'E-Learning Development as Interactive System with Scrum Methodology', in. 2nd International Conference on Vocational Innovation and Applied Sciences 2019, Wyndham Hotel, Surabaya. Available at: http://icvias.com/ (Accessed: 24 October 2020).

Vogelzang, J., Admiraal, W. F. and Driel, J. H. van (2019) 'Scrum Methodology as an Effective Scaffold to Promote Students' Learning and Motivation in Context-based Secondary Chemistry Education', Eurasia Journal of Mathematics, Science and Technology Education, 15(12), p. em1783. doi: 10.29333/ejmste/109941. 